\title{
Observation of Cell Stress: Altered Gene Expression Induced By Acute Chlorpyrifos Toxicity
}

\author{
Elvan Bakar', Aysegul Cerkezkayabekir², Enis Ulucam³, Deniz Aksoy ${ }^{4}$ \\ ${ }^{1}$ Department of Basic Pharmaceutical Science, Faculty of Pharmacy, Trakya University \\ Edirne, Turkey \\ elvanbakar@trakya.edu.tr; aysegulckb@trakya.edu.tr \\ ${ }^{2}$ Division of Molecular Biology, Department of Biology, Faculty of Science, Trakya University \\ Edirne, Turkey \\ ${ }^{3}$ Department of Anatomy, Faculty of Medicine, Trakya University \\ Edirne, Turkey \\ eulucam@trakya.edu.tr \\ ${ }^{4}$ Division of Industrial Microbiology, Department of Biology, Faculty of Science, Trakya University \\ Edirne, Turkey \\ denizyuksel@trakya.edu.tr
}

\section{Extended Abstract}

Chemical methods used in agriculture by pesticides have disadvantages in terms of environmental pollution and human health due to the presence of residues in plant products. Chlorpyrifos (CPF) [O, O-diethyl-O- (3,5,6-trichloro-2pyridinyl) phosphorothionate] is an organophosphate commonly used against garden, agricultural and forest insects. In this study, it was aimed to investigate the effect of CPF on the expression levels of genes that play a role in apoptotic process and determine effect of nucleus gene expression in rat liver.

Wistar albino rats, 200-250 g, were randomly divided into two groups ( $\mathrm{n}=8$ for each). $4.05 \mathrm{mg} / \mathrm{kg}$ (LD 50/10) CPF was administrated to animals by gavage. Liver tissue samples harvested at end-point fixed 10\% formalin for 24 hour and dehydrated and embedded in paraffin. $10 \mu \mathrm{m}$ thick sections of tissue samples were separated for further analysis. High Pure FFPET RNA Isolation Kit was used to isolate total RNA from paraffin embedded liver tissue samples according to the kit protocol. Complementary DNA (cDNA) synthesized from extracted RNA samples using High-Capacity cDNA Reverse Transcription kit and random primers as recommended by manufacturer (Thermo Fisher) and $2 \mu \mathrm{L}$ of the reverse transcription reaction was used as a template at Quantitative real-time PCR (qRT-PCR). SYBR Green I dye Amplifications of PCR product were monitored via which is an intercalator-based method. The cycling program consisted of an initial denaturation at $95^{\circ} \mathrm{C}$ for $10 \mathrm{~min}$, followed by 50 cycles of $95^{\circ} \mathrm{C}$ for $15 \mathrm{~s}, 60^{\circ} \mathrm{C}$ for $1 \mathrm{~min}, 60^{\circ} \mathrm{C}$ for 1 min for all genes. Melt-curve analysis was performed to confirm the specificity of the chosen primers and absence of primer-dimers. Expression quantities of target genes were normalized using GAPDH as an internal gene. Changes in relative expression levels between experimental groups and control group were checked for statistical significance according to Student-t test. The results were considered statistically significant in $\mathrm{p}<0.05$.

Expression levels of SOD, CAT, GSH, HSP70, Lamin, NuMA, PCNA increased significantly by the effect of CPF in liver. Increased SOD, CAT and GSH expressions indicated that presence of oxidative stress in liver cell. HSP70 expression, an endoplasmic reticulum stress marker, demonstrated oxidative stress breaks down into the general cellular stress without a specific target. Parallely, it was obtained that the liver cell responded with increased expression of laminin and NuMA against nuclear stress. PCNA expression also indicated that induced cellular restoration mechanism. But vimentin and topoisomerase expression levels remained. We concluded that the toxic effect of CRP cause cellular stress in liver in rat. 